\title{
Studying Design and Use of Healthcare Technologies in Interaction: The Social Learning Perspective in a Dutch Quality Improvement Collaborative Program
}

\author{
Esther van Loon', Nelly Oudshoorn'2, Roland Bal' \\ ${ }^{1}$ Erasmus University, Rotterdam, The Netherlands \\ ${ }^{2}$ University of Twente, Enschede, The Netherlands \\ Email: vanloon@bmg.eur.nl
}

Received 3 June 2014; revised 18 July 2014; accepted 31 July 2014

Copyright (C) 2014 by authors and Scientific Research Publishing Inc.

This work is licensed under the Creative Commons Attribution International License (CC BY). http://creativecommons.org/licenses/by/4.0/

\section{(c) (i) Open Access}

\begin{abstract}
Designing technologies is a process that relies on multiple interactions between design and use contexts. These interactions are essential to the development and establishment of technologies. This article seeks to understand the attempts of healthcare organisations to integrate use contexts into the design of healthcare technologies following insights of the theoretical approaches of social learning and user representations. We present a multiple case study of three healthcare technologies involved in improving elderly care practice. These cases were part of a Dutch quality improvement collaborative program, which urged that development of these technologies was not "just" development, but should occur in close collaboration with other parts of the collaborative program, which were more focused on implementation. These cases illustrate different ways to develop technologies in interaction with use contexts and users. Despite the infrastructure of the collaborative program, interactions were not without problems. We conclude by arguing that interactions between design and use are not naturally occurring phenomena, but must be actively organised in order to create effects.
\end{abstract}

\section{Keywords}

Quality Improvement Collaborative Program, Social Learning, User Representation, Healthcare Technology, Long-Term Healthcare 


\section{Introduction}

In healthcare, just like many other service sectors, there is enduring attention for improving service delivery in durable ways. How to improve service delivery in such a way that work practices lead to improved quality of healthcare is an important question. This article studies the design and use of healthcare technologies; more specifically care plans and evidence-based guidelines, aimed to improve quality of healthcare delivery in elderly care $^{1}$. Our focus is on the interactions between the development of these new healthcare technologies and use contexts. We therefore empirically explored how healthcare organisations involved in developing technologies tried to integrate use perspective into the design of healthcare technologies.

The idea of integrating design of technologies with use is a subject that is receiving much interest both from the academic world and in healthcare improvement practices. Scholars from a broad range of disciplines, such as innovation studies, organisational studies, science and technology studies and cultural and media studies have for long been involved in trying to understand the relation between design and use and between technologies-in-use, after these have been put on the "market" [1]-[6]. Core in this literature is the idea that interactions between design and use are essential to the process of developing and establishing technologies, and user involvement might lead to a more successful uptake of those technologies into their intended contexts [7].

However, despite all the emphasis on including use contexts in design, it still remains unclear what the effects of these efforts are in terms of more "successful” technologies or more durable innovations. One of the concerns is that design and use (i.e. implementation) are approached as two different and often successive phases. Most studies however, acknowledge the need for interactions between design and use, but predominantly focus either on the design or the use "phase". The risk is that conclusions are drawn too quickly about success or workability of technologies. Scholars following the social learning approach therefore argue that such "snapshot" studies, focusing on short time periods can result in biased claims about the way technologies work and succeed in realising durable changes [8]-[10]. Scholars adopting the social learning perspective argue that design and use are not two separate and successive "phases", but should be understood as iterative processes with multiple feedback loops between design and implementation. In order to understand the relation between design and use and their consequences, social learning approaches propose that more in-depth and longitudinal studies involving different types of actors on the evolvement of design are necessary.

In this article, we follow ideas from the social learning perspective in seeking to study design and use in interaction. We undertook a multiple case study, based on our research within a Dutch quality improvement collaborative program for long-term care, called Care for Better (Zorg voor Beter). This approach enabled us to go beyond snapshot studies, because it focuses on multiple projects initiated by multiple healthcare organisations, which we studied at multiple times.

Care for Better consisted of Development Projects and Improvement Projects. In the Development Projects, healthcare technologies for improving care delivery were developed by several national quality improvement organisations. Being part of Care for Better, these organisations had the task to design these technologies in close collaboration with healthcare practice through the Improvement Projects. These Improvement Projects focused on specific topics for improvement, such as medication safety, problem behaviour and eating and drinking and teams of care organisations joined to address these issues collectively and in their own organisations [11] [12]. Integration between these two parts of Care for Better was seen as essential and serves therefore as an exemplary case to study interactions between design and use that intend to move beyond snapshots.

The research question of this article is: How can we understand the attempts of healthcare organisations to integrate use perspectives into the design of healthcare technologies? We structure the article in the following way: First, relevant literature on the design-use relation is discussed. We discuss literature that focuses on representing the user in design, followed by a discussion of the social learning approach and its aims. After explaining the methods, Care for Better is analysed as an infrastructure for supporting social learning. Three empirical cases of Development Projects that tried to integrate use and design are then analysed and show the actions that were undertaken to represent the user and integrate design and use. Our data show that even when most actors generally agreed upon the idea that integration between design and use is worth striving for, this

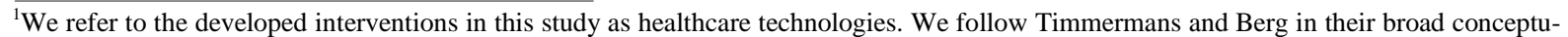
alisation of technologies: “...leads thus to a broad definition of technologies, including the entire gamut of mundane to sophisticated technologies, drugs, and even managerial instruments such as patient records. Actually, in this approach it is difficult to single out one technology as an isolated device because technologies are embedded in relations of other tools, practices, groups, professionals, and patients and it is through their location in these heterogeneous networks that treatment, or any other action, is possible in health care.” ([30], p. 104)
} 
alone was not enough to realise sharing of knowledge and experiences and learning amongst different actors. Practical aspects and different opinions were often obstacles in the collaboration. The article concludes by arguing that interactions between design and implementation do not occur naturally but must be organised in order to create feedback between the two.

\section{Interaction between Design and Use of Technologies for Innovation}

\subsection{Images of User in Design}

Interaction between design and use starts with the design of a new technology. Designers create images of future users and the broader world in which those (to be developed) technologies should be embedded (i.e. the evolvement of morality, science and economy).

An exemplary study that investigated the relation between design and use is Woolgar's study of the manufacturing of a micro-computer. He compared the design of a machine with a text and argued that a text is written with a specific public of readers in mind. By writing a text the authors inscribe particular readers (users) in the text. The same holds for material technologies, which are designed for a specific public and a specific use [13]. Although Woolgar's work has been influential in getting a better understanding of the role of use in design processes, his work has also been criticized. Woolgar grants the designers a rather authorative role in inscribing the user in design [4] [5] and leaves too little room for the interactions between designers and users in creating technologies [14].

By doing in-depth case studies of the design of technologies, Madeleine Akrich explains how in the design phase of new technologies, designers anticipate the interests, motives, skills and behaviour of future users [4] [15]. These user representations are then inscribed into the (material) technology. The result is a "script" or "scenario" [15]. The representation of users is not a one-way process from design to use, but:

"Instead we have to go back and forth continually between the designer and the user, between the designer's projected user and the real user, between the world inscribed in the object and the world described by its displacement.” ([16], pp. 208-209)

This process, which Akrich refers to as description, allows for feedback in design processes and grants room to users for modification of the design. How to represent the projected or the real users is one of the core concerns in studies following the semiotic approach advanced by Akrich and Woolgar. Akrich described implicit and explicit techniques for user representation [17], among which the I-methodology is often cited. The Imethodology means that designers rely on their own personal experiences as a representation of the users [17] [18]. This has its disadvantages. Feminist scholars argue how diversity, including gender is often absent in user representations for design of technologies [4] [18] [19]. For example, Neven shows how in the design of a robot to assist in home living for elderly, its designers portray the intended users in homogeneous and stereotyped ways. As a consequence these designers invited a random group of elderly to test the robot. However, the elderly that tested the prototype robot did not project themselves as the users of the technology, as it was intended for frail elderly, with impairments and disabilities, but "obviously not for them" [20]. Such studies, following the semiotic approach, show that broad categories such as "the elderly" or "nurses" or "the Dutch population" are often too specific for more targeted (healthcare) technologies and it requires close scrutiny to find more actual or real users of a technology.

Although semiotic approaches do not consider technologies finished when they enter the "market", most studies tend to focus mainly on the design processes and the ways users are represented in design. Most semiotic studies are done by performing in-depth case studies and undertaking ethnographic work. These methods are rich in detail and therefore interesting to understand the consequences of design choices. However, it is hardly possible to tell things about the effects of the representations of users in design over time, most importantly for the actual use of the technology when following this stream of literature [5] [10]. We therefore turn to another approach in studying design-use relations, the social learning perspective.

\subsection{Moving Beyond Snapshots: Social Learning Perspective}

Another branch of literature that focuses on design-use interactions are social learning perspectives. Social learning perspectives have their roots in economic studies. Learning by doing, a central concept in this approach, refers to more efficient manufacturing of goods, due to increased knowledge of how to produce the good ([21] in 
[9]). Rosenberg distinguishes disembodied learning (learning how a technology works through its use) and embodied learning (learning by using leads to design modifications) [5] [22]. The latter is important in understanding the interactions between design and use.

Core in the social learning approach is the long cycle that should explain how innovation develops [8]-[10] [22]. The idea is that the ways that innovations work can only be understood when looking at longer waves or cycles. Social learning is thereby a collective learning process. Stewart and Williams note:

"The social learning perspective on design thus locates design within a broader context. Episodes of design are not viewed as snapshots in isolation - temporally from what precedes and follows it, or socially from its broader context-but are seen as moments of innovation across multiple cycles of design, implementation, consumption and further enhancement that are dispersed across a wide range of players, sites or phases." ([5], p. 204)

Following these multiple cycles or feedback loops is considered essential to analyse the changes that occur in innovations and understand the consequences of the interactions between design and use. Innovation is not a linear process that starts with design and evolves into use, but instead is circular and dynamic. The social learning approach acknowledges the importance of including users in designs, although it challenges the presumption that including users in design is the primary solution to meeting design and implementation problems. Instead, their core interest is that the linearity of design and implementation should be questioned [5].

Social learning perspectives consider longitudinal studies, whereby multiple layers of actions are studied at different time intervals as the best way to study innovations. Moreover, there should not be a too narrow analysis of just the technologies and their interactions, but a broader perspective should be adopted [9]. This longitudinal and intensive way of studying design-use relations can bring a better understanding of how innovation can "work" and it should prevent "snapshot" analysis of design-use relations [9] [10].

However, current funding policies in Europe have resulted in R \& D practices that usually involve short projects. Adopting a long-term perspective is therefore not always adequate to study these practices. We therefore explore an alternative approach. We study initiatives of healthcare organisations that adopted a project-based approach to integrate design and use. The study of the Care for Better quality collaborative program provides an infrastructure that helps to study design-use interactions in a shorter period of time. This is interesting as it can bring important insights in possibilities of studying multiple cycles of interaction between design and use in less longitudinal ways than social learning perspective propose. How we set up this study will be explained in the next section.

\section{Studying Design and Use in Interaction: Background and Methods of Research}

Care for Better is a quality improvement collaborative program that was set up by the Dutch Ministry of Health to serve as an infrastructure for working on innovations in long-term healthcare. The collaborative program started in 2005 and aimed to improve quality of care at the level of clients and care professionals. The evaluation of this collaborative was undertaken by the Department of Health Policy and Management, involving a research team of nine persons, among which the first and third author of this article. This evaluation started in 2007 and was done by using both qualitative and quantitative research methods and, where possible, combining those in mixed-methods approaches [23]. The research team collected data on the client, project, organisational and program level.

One element of the Care for Better collaborative were the Improvement Projects (see also: [12] [24]). In these projects, specific situations of the work floor level were tackled, such as addressing problem behaviour, client centred care, medication safety or taking care of incontinent clients. The Breakthrough Series, as developed by the Institute for Healthcare Improvement, served as a basis for the Improvement Program. The Breakthrough Series is a learning system, in which teams of care workers learn methods to improve care on a specific topic. The idea behind this system is that by setting up a structure in which teams of care organisations learn and share insights and are supported by experts, a "breakthrough" can be realised [25]. Parts of the Breakthrough Series are Plan Do Check Act (PDCA) cycles. Teams learn new methods for improving care, they go back to their organisations and test these new approaches, come back to share their results and insights at a successive meeting, and so on. Such iterative and reflexive learning approaches show similarities with the social learning approach, that also urges for more feedback loops in learning and understanding improvements.

One year after the start of the Improvement Projects, the Development Project became part of Care for Better, 
with the intention to develop healthcare technologies to improve quality of elderly care. Several joint organisations in the domain of elderly care (such as professional organisations for nurses and elderly care physicians, the ministry of Health and the Healthcare Inspectorate) agreed upon norms for responsible elderly care. These norms were to be carried out in the Development Project in the form of the development of healthcare technologies. Care for Better was seen as an important infrastructure for the Development Project. Elderly care organisations that took part in the Improvement Projects could bring valuable insights for the user representations that were sought in the development of the technologies and collaboration with the Improvement Projects could ensure a more fluent implementation of the technologies. Both the Development and the Improvement Projects addressed to a great extent the same topics. For example there was an Improvement Project on continence care and within the Development Project an evidence-based guideline on incontinence was developed. This congruence in topics should ensure a close collaboration between design and use.

$\mathrm{We}^{2}$ studied 6 of the 24 Development Projects of Care for Better in depth, using qualitative research methods. Three of the most promising and illustrative Development Projects have been analysed for this article: the evidence-based guideline for urine-incontinence, the multidisciplinary guideline for problem behaviour ${ }^{3}$ in elderly care and the Care Living Plan. These cases were most interesting for this article, as they were the most exemplary in their effort to integrate design with use and in representing the user. All three cases were largely different in the approaches they undertook and in creating feedback loops or cycles between design and use. All data collection took place between 2007 and 2012.

The urine-incontinence case was followed in 2008 and 2009. It involved the development of an evidence-based guideline for incontinence in (frail) elderly. A professional organisation for nurses ( $\mathrm{V} \& \mathrm{VN}$ ) was responsible for the development of the guideline for urine-incontinence, but the Netherlands Centre of Excellence in Nursing (LEVV), a knowledge institute for improving nursing practice, executed the project. We observed expert meetings (3) of the guideline development group and interviewed the guideline methodologist of LEVV and the project coordinator of V \& VN. Our focus was predominantly on the activities and experiences with organising interactions with the Improvement Project and the ways that users were represented. We observed two meetings held by the Improvement Project on incontinence and interviewed the project leader of this Improvement Project. Aim of these efforts was to understand the relation with the development of the guideline. Documentary sources as the guideline text (both draft versions and the final version), minutes of the expert meetings, the plans and evaluation of the improvement project were analysed as well.

The problem behaviour case included the development of the multidisciplinary guideline on problem behaviour and an Improvement Project on problem behaviour. We studied the guideline development by attending the guideline development group meetings and analysed the meeting minutes of this group. The project leader of the guideline development was interviewed twice (in 2008 and 2011). Three meetings of the improvement project were observed and the documents of the improvement team (project application, evaluation of the project) were analysed. A successive project (2010) to further spread the guideline was followed by attending the meetings of the project team (4), joining a visit to one of the involved healthcare organisations and analysing the documentary sources and products that were created as part of this project. Further, a case study was done in an elderly care facility that tried to spread the guideline in the organisation (2011).

The Care Living Plan (CLP), the third case, is a care plan for elderly care that should stimulate client centred care. The project was executed by Sting, the professional organisation for geriatric assistants. We interviewed the project leaders of Sting twice and held regular phone calls with these project leaders of which notes were made, about how the project advanced (2008-9). We gained important insights into the ways the users were represented. We did a case study in an elderly care facility in 2009 that developed and implemented the CLP, showing us the dynamics of developing the CLP. Meetings for team leaders and coordinating nurses were observed (4) and documents were analysed (such as project plans and (draft) Care Living Plans of organisations) ${ }^{4}$. The analysis of the ways in which healthcare organisations tried to integrate user perspectives in the design of the healthcare technologies developed in these three cases was based on an investigation of the ways in which they represented the user and whether and how the organisational infrastructure supported social learning proc-

\footnotetext{
${ }^{2}$ The first author did most of the fieldwork. Some of the fieldwork has been done by colleagues from the Institute of Health Policy and Management who where involved in the Care for Better evaluation. The three authors of this article were all intensively involved in the data analysis. We therefore refer to "we" in the description of the undertaken fieldwork.

${ }^{3}$ Problem behaviour is the term chosen by the projects themselves. It refers to all the behaviour of clients that is considered to be problematic by clients or their environments [29].

${ }^{4}$ The cases on problem behaviour and the Care Living Plans were discussed in previous work, see [27] [31].
} 
esses.

To understand the role of the funders and organizers of Care for Better, interviews with representatives of ZonMw (2), and the Ministry of Health (1), were held. ZonMw is the Netherlands Organisation for Health Research and Development and was appointed as the executor of the Care for Better program by the Ministry of Health. These interviews were done in 2008.

Before presenting the analysis of the cases, we first discuss the policy-intentions of the Development Program and the Ministry of Health to better understand the set up of the program.

\section{Care for Better as an Infrastructure for Reinforcing Social Learning?}

At the start of Care for Better, around 2005, quality of long-term care was a hot topic. Several alarming reports were published on the marginal quality of care delivery in long-term care, especially in nursing homes, and the media reported on "pyjama days", referring to elderly in nursing homes that should stay in their pyjamas due to shortage of staff to take care of them. The Ministry of Health urged for an integration of quality improvement initiatives in long-term care, which should result in sharing and building bridges between the otherwise separate initiatives in long-term care. Care for Better became the umbrella under which several other projects were brought. The responsible policy officer of the Ministry of Health explained the reasons for this integration:

“The explicit intention of Care for Better is that connections arise, between Care for Better innovation, Improvement Projects and what happens in the Development Program. Ideally you should say: what they [i.e.

Development Program] develop should be implemented here. It should land somewhere, bridges must come into existence.” (interview policy officer, Ministry of Health)

The intentions of the Ministry are that connections will arise between different parts of Care for Better and that such bridges help to implement the developed healthcare technologies. The policy officer however, does not emphasise feedback loops to design. She noted that implementation could benefit from these bridges rather than the development of the technologies. Moreover, she explicitly argued that connections should arise and come into existence. She did not mention that these bridges should be explicitly organised. As we will see later, especially in the case of incontinence care, bridges do not emerge out of nowhere. Instead, without persons willing to invest in building these bridges nothing will happen.

Initially, the Ministry opposed the inclusion of the Development Projects under the Care for Better umbrella, as the organisations applying for funding re-applied with earlier projects that the Ministry had disapproved of as they considered the quality to be insufficient. Eventually, also due to political pressure, the Ministry approved, but stressed the point that it should not "just" be development of technologies, but these loose initiatives should be embedded into the Care for Better program:

"Well our argumentation was, and it was not ideal, to do it rather well founded. Thus, in the Development Program technologies are made and these are being offered to the Improvement Projects that match the topic. For many of the projects this should be feasible. For example, if there is a guideline on incontinence care this can be taken along in the Improvement Project on incontinence. If there is no Improvement Project on the topic we must investigate whether Care for Better offers other ways to implement it.” (interview policy officer, Ministry of Health)

Throughout the interview with the policy officer it became clear that integration of developed technologies in the improvement projects was the aim, and not the creation of feedback loops between design and use. This had implications for the way the whole Care for Better collaborative was governed.

The Ministry appointed ZonMw was the executor of the Care for Better program with the assignment for being responsible for both the supervision over the development and the implementation of all the initiatives. ZonMw coordinated the program by deliberating and constant tuning with all involved stakeholders, such as the steering group and advisory board of Care for Better, making sure that appointments were being met, and keeping all parties motivated to remain part of Care for Better. One of the program coordinators of Care for Better explained:

"Within the Development Project we constantly kept saying, if you have developed this and it is suitable, we must integrate it into the Improvement Projects. And we urge them [i.e. the developers] to not set-up another loose initiative to implement it in another way. We notice that it is essential to continuously guard 
this vision. [...] You are part of this big umbrella, so learn what we do in the Improvement Projects. It is necessary to constantly repeat this message.” (interview policy officer A, ZonMw)

ZonMw was very aware of the ambition of the Ministry to make Care for Better a program that was not just a collection of loosely coupled small projects, but instead aimed for alignment and coordination. Still, the assumption here is also that designs are "finished" products that need to be implemented into care practice. Modifications by users or feedback loops were not part of the program. The way the program is set up therefore seems to align more with a diffusionist' account of how innovation works [26] than a semiotic or social learning perspective.

ZonMw remarked that the internal organisation and division of specific coordination activities regarding Care for Better hindered a good coordination over the collaborative program. For example ZonMw was organised by having different financial and coordination divisions for the different Care for Better program. This was considered problematic, as it needed constant coordination between the different divisions. When the Care for Better collaborative program gradually expanded, this organisational division became more troublesome.

The intentions of the Ministry and ZonMw are thus to combine initiatives under the Care for Better umbrella in order to embed developed technologies within care practice. Underlying this is a linear way of looking at how innovations proceed. However, the Development Projects itself held a different view. Their intentions were to create space for feedback loops between design and use. The project application of the Development Project stated this as follows:

"Through integration of the Development and Improvement Program a system is created in which developed instruments ${ }^{5}$ can be implemented quickly and which generates time and money to react to signals which become visible when developing instruments.”

According to the Development Project, interactions should yield benefits both for implementing the technologies as well as reacting to signals of users for the development of the technologies itself.

The Development Project and the Care for Better organizers thus hold different perspectives on the need to integrate the Development Project with Care for Better. The Care for Better organisers strived for integration of different activities and smoother implementation, whereas the Development Project aimed for feedback loops between design and use. These different perceptions had consequences for the way the program was steered and the interventions that were undertaken. We will now zoom into the three cases subsequently to show how interaction between design and use was organised and to what consequences for the development and use of the technologies.

\section{The Care of Incontinent Clients: The Problem of Representing the User}

The first of the three projects was focused on incontinence care. Within the Development Project an evidence-based guideline for urine-incontinence in the care for (frail) elderly was developed. An Improvement Project on Incontinence care was held at the same time. Different organisations were responsible for the projects: a professional organisation for nurses (V \& VN) was responsible for the development of the guideline, but The Netherlands Centre of Excellence in Nursing (LEVV), a knowledge institute for improving nursing practice, executed the guideline development. Vilans, a knowledge institute for long-term care, executed the Improvement Project. Coordination between design and use should therefore be found in cooperation between different organisations. The execution of the project is visualized in Figure 1. A policy advisor of V \& VN held the position in between these two projects. He was responsible for the guideline development and also participated in the core team of the improvement project on incontinence. However, despite the Care for Better infrastructure, and despite that the V \& VN policy advisor who was involved in both projects, the interaction between the two projects was largely absent and several problems were encountered in representing users in the guideline.

For the developers of the guideline it seemed difficult to represent the user in the development of the guideline. The guideline was a multidisciplinary guideline addressing several different care workers in elderly care, such as geriatric assistants, elderly care physicians and nurses specialised in incontinence care. The guideline development group, further referred to as the expert meeting, consisted of experts from the field of incontinence care, such as a pharmacist, a district nurse, nurses specialized in oncology care and continence care, an elderly

\footnotetext{
${ }^{5}$ Instrument is the term as used within the Care for Better collaborative. We use the word (healthcare) technology in this paper, as the word
} technology better aligns to the word most often used in literature on design/use interactions. 


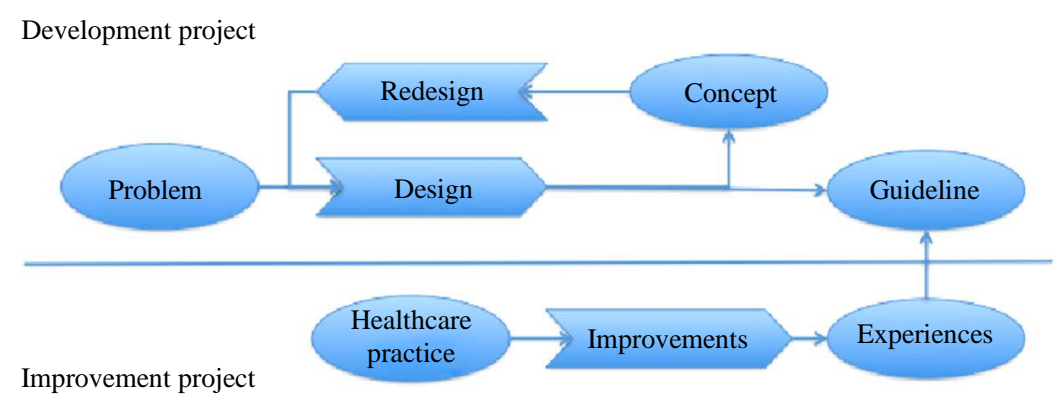

Figure 1. Flowchart of urine-incontinence case.

care physician and a pelvic physiotherapist. A guideline methodologist of LEVV was in charge of the expert meetings, assisted by a trainee. This group met every few months to discuss the evidence that was selected by the guideline methodologist and were written down in draft texts of the guideline. In those meetings, the texts were central and were constantly compared with what happened in practice, what seemed feasible and what experts assumed as accepted by the end-users of the guideline. In terms of Akrich, the expert group anticipated on the skills, demands and behavior of the healthcare workers to inscribe these in the guideline. Since the expert meeting members worked with incontinent elderly, they could own expertise in the work with incontinent elderly. Akrich describes such ways as implicit techniques of representing the user. By relying on their expertise they were able to alter, nuance or subscribe to the suggested recommendations based on (scientific) evidence. For example, evidence stated that drinking too much carbonated drinks would increase incontinent complaints. The expert meeting members nuanced this finding as they noted that elderly do not often drink carbonated drinks in the first place.

Besides these implicit ways of representing the user, more explicit representation techniques were also undertaken. One of the ways to do this was to acquire inputs from healthcare practitioners that are involved in caring for elderly with incontinence and elderly with incontinence themselves. The latter can be considered indirect users of the guideline. In the expert meetings, there was much attention for including elderly with incontinence in the development process. To reach this group, the guideline developers send out a call via several general client associations to invite clients with incontinence problems to a focus group meeting at the office of LEVV in Utrecht. Clients were reimbursed for $€ 75$, for attending the meeting. There was no single response to the call. The expert group discussed the possible reasons. They assumed that the taboo on the subject might be of influence, and perhaps practical reasons such as mobility or physical situation of the clients. Moreover, the question was raised to what extent a focus group meeting was the right intervention to be able to reach these frail elderly, instead of perhaps other more mobile and active elderly, that were not considered the target group of the guideline. The fear was that addressing elderly without these complaints could lead to consequences even described as "obviously not for me" [20]; the real users were not reached and the consulted elderly regarded themselves as inappropriate for the guideline in question. Eventually, the elderly care physician organized a meeting in the nursing home he worked in, to discuss incontinence care with eight elderly clients. The trainee of LEVV joined this meeting and several experiences were gathered for the guideline development, such as the taboo on the subject and practical hindrances in the way the ward was constructed. Elderly in other forms of care, that was considered the target group of the guideline, such as home care or elderly in hospitals were not included in this explicit representation technique.

Next to elderly clients, also four professional groups in elderly care were explicitly addressed in the guideline development. An inventory was done, in the form of a digital questionnaire, to investigate the bottlenecks of care for elderly with incontinence problems among geriatric assistants, nurses with specialty in continence care, physiotherapists and elderly care physicians $(n=110)$. During the expert meeting the outcomes of the focus group with patients and the questionnaire were discussed.

After all the efforts to gather these representations of the patients and professional groups it was surprising that little was done with it in the development of the guideline. The outcomes of the focus group meeting and of the questionnaire were put in an appendix of the guideline that served as additional information of the justification of how the guideline was made. The representations were thus hardly inscribed into the technology. The project leader of LEVV remarked in an interview that not each "hurdle" could be addressed in the guideline, due 
to financial restraints of the guideline development and the lack of evidence to support some of these points. Only in one instance the guideline referred to the focus group meeting, by remarking that physical space matters, as obstacles like wheel chairs and other equipment on toilets or hallways can obstruct the route and sometimes result in reaching the toilet too late. As far as the questionnaire actually impacted the definitive guideline remains hard to discern, it should serve to determine the central questions of the guideline, as stated in the justification of the guideline, but the results of the questionnaire were known only halfway the guideline development process. This seems to suggest that the explicit ways to gather user representations in the guideline development were only marginally included in the content of the guideline. Instead, the I-methodology and the reliance on personal expertise of the guideline development group were dominant in gaining a representation of the user.

The Improvement Project, in which experiences of healthcare workers involved in the subject were widely shared, could have been an accessible place to get a good representation of the future users. Yet, this collaboration never commenced. LEVV and Vilans did not cooperate, as different perceptions of each other's approaches existed. LEVV felt that the Improvement Project was too practical, without any interest in the evidence behind urine-incontinence. The Improvement Project members disagreed on this by arguing that they also based themselves on scientific insights, complemented with more practical experiences. Vilans, the executer of the Improvement Projects, on its turn, criticized the draft guideline in a written document. Among its criticism, it claimed that the guideline developers were too much involved with the evidence, making the guideline a "technical document”, without taking notice of the practical feasibility of recommendations. For example, they argued that workload in nursing homes is high and several of the suggested interventions were unrealistic, even though these are evidence-based. Also, some of the proposed interventions, like pelvic training, were thought to be unattainable in the target groups. Clashes as these made it difficult to initiate interactions between design and use. Instead of collaborating, divergence between the development group and the improvement group emerged. The policy advisor of V \& VN, who was involved in both projects, did not undertake action to prevent or reduce this gap. Interestingly enough, he was the first author of the written document of Vilans that criticized the guideline.

Summarizing, our analysis of the case of incontinence showed the following dynamics of interactions between design and use. First, representations of the users were collected in implicit and explicit ways, whereas the implicit ways seemed to align to the guideline development process in easier ways. Through discussion between the expert team members decisions were made about what to include and exclude. Information stemming from the questionnaire and the group conversation with the elderly, was more difficult to include in representations of the user and therefore mainly ended up in the appendix of the guideline. A second aspect of this case is that collaboration with the improvement project did not take place. In the context of this paper it is less relevant to explore the differences in opinions and the clashes between the development and the improvement projects. More of relevance is to note that bringing two projects under the Care for Better heading does not automatically mean that integration and collaboration occurs. Other things must be done to realise feedback loops. The next case brings an example of how feedback loops did occur between development and use.

\section{Problem Behaviour in Elderly Care: Social Learning without Implementation?}

A second evidence-based guideline that was developed within the Development Project of Care for Better was the guideline for problem behaviour in the care for elderly. This guideline consisted of two parts: the guideline with recommendations based upon evidence and an action plan involving nine steps to improve problem behaviour. Here, the interaction between Development and Improvement Projects was realized in more substantial ways, and this interaction led to several feedback loops. These interactions are visualized in Figure 2. This project was felt to be a success story, as the project leader of the guideline development remarked after the guideline was finished:

"I think that if you look at how the Improvement Projects were initially set up, and how we want the things to go, this is sort of a textbook case of how it should have worked out with many of the other projects. Aspect of guidelines were so useful that these served almost directly as input for the healthcare practitioners and experiences of the Improvement Project could be taken along in the guideline." (interview project leader guideline development and member of the Improvement Project)

One instance later, she "corrected" herself that this was more or less a coincidence, or perhaps the right persons on the right places that made it possible to be able to realize this collaboration. By being sensitive of which 


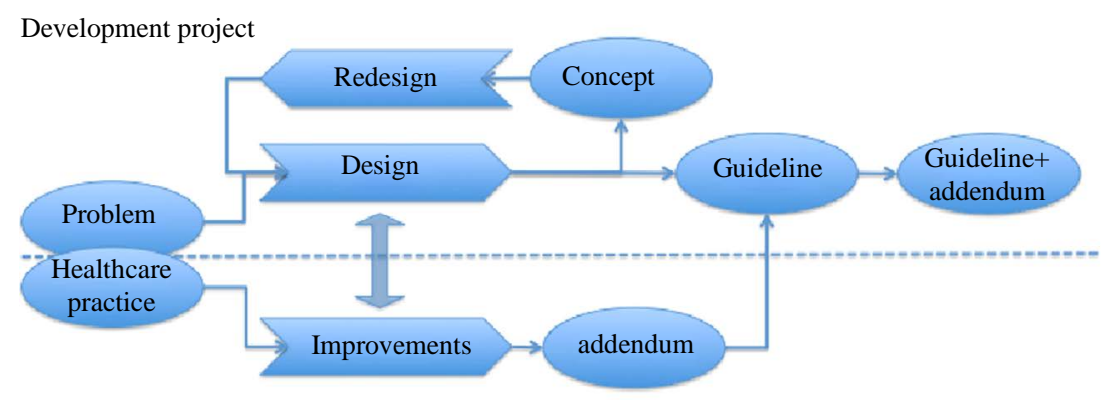

Improvement project

Figure 2. Flowchart of urine-incontinence case.

aspects could serve both the development and the implementation, sharing and learning was reached. This approach thus seemed to be aimed explicitly at social learning.

The guideline development was the responsibility of Verenso, the professional organisation for elderly care physicians. The guideline was a revision of an earlier mono-disciplinary guideline on problem behaviour. The reason to revise the guideline was that the medication paragraph needed an update, and the guideline was supposed to become multidisciplinary, instead of a guideline solely for the elderly care physician. The prior guideline was monodisciplinary and Verenso had noticed that this guideline was difficult to implement; problem behaviour was too complex and in need of the coordinated involvement of all health care workers in elderly care. Verenso was responsible for the guideline development, but also participated in the core team of the improvement project on problem behaviour, that was chaired by Vilans. So it was perhaps more than a "coincidence with the right people on the right places" as mentioned by the project leader. The project leader of the guideline de- velopment was in the position to make important linkages between design and use contexts.

The Improvement Project turned out to be a relevant infrastructure for the multidisciplinary aims of the guideline group. There were three subsequent so-called "rounds" of the Improvement Project on problem behaviour. The first two rounds were held simultaneously with the guideline development, and organisations in elderly care and care for intellectually deficient participated. The third round took place after the development of the guideline. In total, more than 30 different organisations participated in the Improvement Project.

In the improvement project, teams of healthcare organisations in long-term care learned how to assess, diagnose and take action to solve or reduce problem behaviour of clients in a multidisciplinary way. This required intensive collaboration and deliberation among teams as the definition of which situation was or was not problem behaviour is dependent on the context, the involved persons and their personal and professional values ${ }^{6}$. The Improvement Project introduced a stepped-wise method consisting of nine steps to assess, understand, take action and evaluate the interventions taken to approach problem behaviour. This was based upon the guideline. In the Improvement Project, teams learned to use the nine-step method and shared their experiences in using it. This Plan Do Check Act approach, which is part of the Breakthrough Series, was the backbone of the Improvement Project. The approach adopted in this project clearly reflects core aspects of social learning. The experiences of the teams were not only of relevance for the other teams, but also for the core team that used these insights to get a better view of the actual applicability of the method in practice. This allowed them to make modifications in the nine-step method as they discovered where the bottlenecks were for the teams and where some extra attention was warranted. For example, the core team noticed that care workers often neglected one of the steps, which was defined as "understanding the behaviour of the client". Healthcare workers rather "rushed" from observations towards actions, without defining what was going on. By knowing these tendencies of the teams they paid extra attention to this step in the descriptions in the guideline and in the further implementation of it.

As the experiences with the method were positive, the nine steps eventually became part of the guideline. The guideline remained primarily focussed on the work of elderly care physicians, but an addendum was added for the other care workers, such as geriatric assistants, nurses and psychologists. And by testing and experimenting with the methodological steps so intensely, Verenso knew that the guideline had much potential to improve the care of clients with problem behaviour.

After the guideline was published, Verenso, Vilans and the professional organisation for geriatric assistants

${ }^{6}$ See for more information [31]. 
(Sting) bundled their capacity to spread the guideline among new organisations and learn if there would be extra interventions needed to spread it. Five elderly care organisations participated. An inventory in these organisations was made of their needs to be able to better understand how to spread and sustain the guideline. This was done amongst managers or directors, geriatric assistants/nurses and elderly care physicians and sometimes also psychologists. As these organisations used to participate in the first or second round of the Improvement Project, they were knowledgeable of the improvement methods to reduce problem behaviour. They did not get to use the guideline and the addendum then, however, as these were still under development. The inventory in these five organisations was used to determine if additional tools were necessary, as especially Sting assumed that the addendum in its current form was not appealing to the geriatric assistants. The five organisations showed that spread and sustainability of the used methods in the organisations was not commonplace. Most of the organisations struggled with how and when to use the nine-step plan, and some organisations did not use the method, or paid no specific attention to problem behaviour any longer. Part of the problem seemed to be the lack of time. Especially geriatric assistants explained that they did not have sufficient time to deliberate with colleagues or to consult the elderly care physician, due to being occupied with direct care work. Moreover, some of the organisations mentioned that they lacked a shared and unified approach towards problem behaviour. However, the nine-step plan is fully aimed at finding a common ground for understanding problem behaviour together as a team, and the guideline acknowledged that a common definition or demarcation of what is or is not problem behaviour cannot be given beforehand. The lack of time, as mentioned by geriatric assistants can be a problem in getting this project to start. Interestingly, here Verenso, Vilans and Sting did not feel the need to make adjustments to the guideline. As they got confident that the nine-step model could work, they focused at accompanying the organisations in making the change, instead of adjusting the guideline. This project thus shows that feedback loops between development and use therefore do not always lead to further adjustments to the design itself.

A different project on problem behaviour was focused on the implementation of the guideline on an organisational level. A nursing home that participated in the Improvement Project took numerous steps to improve care for elderly with problem behaviour in their organisation. The guideline there served as a fundament for changing the way of thinking and approaching clients ${ }^{7}$. Here, the lack of time was also an issue, but the project leader of the organisation did her best to spread all the prior results of following the guideline to show others that the investment of time would pay back in the end when problem behaviour was reduced.

The experiences in the development and implementation of the guideline for problem behaviour show that interaction between design and use can take place in a short period of time. Moreover, it showed that such interactions are important to create technologies that meet some of the needs of user groups. How to represent the user was not a problem here, in contrast to the first case. Users were enrolled rather informally, by being part of the Improvement Project. However, implementation problems, such as the lack of time, were still present.

\section{The Care Living Plan: Local Technologies Struggling with Standardisation}

The Care Living Plan (Zorgleef plan) is a compulsory plan for elderly care facilities to provide care in client-centred ways ${ }^{8}$. In many elderly care facilities direct care was still given in ways that merely suited the organisation, and was dominated by a focus on providing medical or physical care. In line with recent trends, care delivery for the elderly was believed to need to change towards a more client-centred care giving and the Care Living Plan (CLP) should facilitate this change. Instead of being a normal care plan, this plan explicitly involved (and gave more coordination to) the client by putting their wishes central. Not only physical care aspects should be included, but also the domains of living situation, social participation, and mental well-being should be addressed. These four domains were essential elements of the CLP.

The professional organisation for geriatric assistants, Sting, was responsible for the development and implementation of the CLP, as part of Care for Better. Instead of seeking to align to an Improvement Project, Sting took a different route and experimented with accompanying elderly care organisations in developing and implementing their own local CLP, customized to their specific organisational needs. In Figure 3 the interventions of Sting are visualized. Sting did not interact with other Care for Better projects, although ZonMw strongly recommended them to do so.

Sting instead chose for its own approach, in which development and implementation was to be arranged at the

\footnotetext{
${ }^{7}$ See also [31].

${ }^{8}$ See also [29].
} 


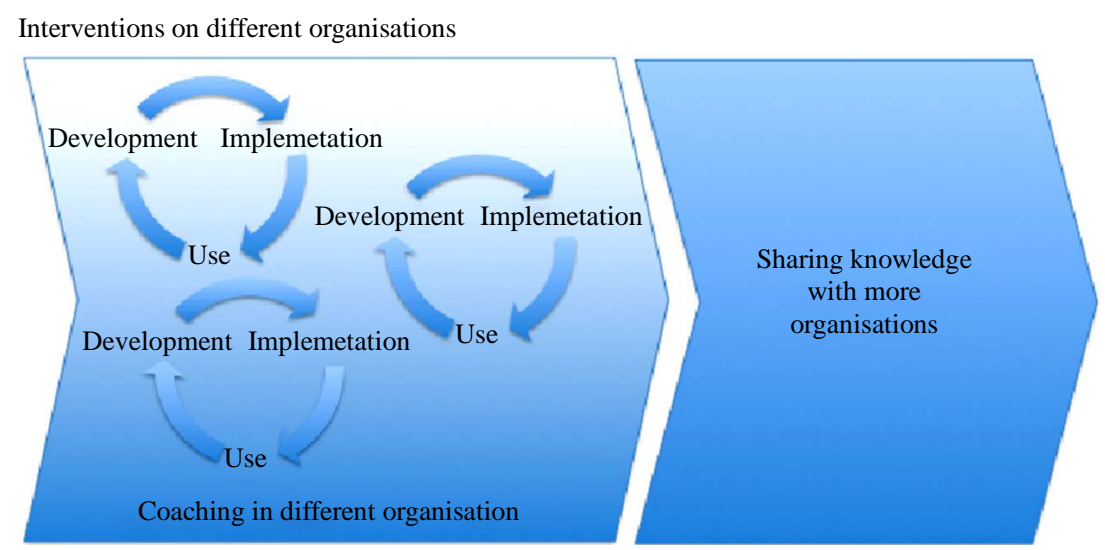

Figure 3. Flowchart of care living plan case.

level of elderly care organisations. Sting wanted to secure that this was not "just" an implementation of a technology, but instead was a change that affected the culture and the way of doing things in the whole organisation. The project leader argued in an interview about their approach:

“People assume that we do a 'project implementation' Care Living Plan in which we set a date and arrange that on that date all wards are working with the plan. If we would do that, we would be implementing the tool and we would not be focused upon the results. If we would focus upon the results we would need to ensure that all clients have a Care Living Plan that supports them into living the live that they want to." (Interview project leader CLP)

Their aim thus was to make durable changes in thinking and organizing care in more client-centered ways. Not "just" to implement the tool. To do this, Sting chose to support organisations in developing and implementing their own Care Living Plan. There were several models of the CLP on the market, developed by national care institutes, but it was up to the organisations to either choose a model and adapt it or to create their own suited CLP as long as the plan was in line with addressing the four domains and aimed to put the client central in the care process. Developing and implementing their own CLP should stimulate organisations to include local knowledge from users of their organisations into the design of the CLP. As a result, the organisational CLP should be better able to meet specific organisational needs, and be easier to implement. In such a way, user representations were sought locally and also social learning and feedback on the design was stimulated at an organisational level, making the reaction time to adaptation of the technology more direct. Sting organized meetings with nursing team leaders of different care organisations. They also provided individual coaching to five elderly care organisations and launched a website with tips and tricks, experiences and best practices aimed to spread their knowledge to other organisations.

In representing users, most of the organisations noticed that the heterogeneity of user needs posed tensions for deciding what should be included and excluded in the CLP. The organisations were accompanied to form a multidisciplinary delegation of care workers and managers, who together created a concept CLP for their organisation. In such a way, it was assumed that relevant local knowledge was reflected upon and could serve as input for the design of the CLP. However, things turned out to be not that simple. For example, specific elderly groups required different approaches. For example, elderly admitted for a short time recovery from hospital admittance did not need a full interrogation about their life history, in comparison to "regular" long-time clients. And elderly with (suspected) memory problems needed extra attention for their brain capacities than elderly without these complaints. How to reconcile this in the CLP without making it a lengthy and unworkable document was a real puzzle.

Despite these large differences, all organisations in this study strived for one uniform CLP that should serve the whole organisation. This meant that local differences were to a certain extent "polished" or aggregated. A quote, from an interview with an organisational project leader CLP can illustrate this:

"You are faced with a lot of differences per unit. Some units have, for example, many clients with a multicultural background and things just go differently there. So we had to emphasize constantly, it's not about 
the individual; it's about the common denominator. What do we all have in common? That was a great barrier.” (Quote adapted from earlier published material: 27, p. 131)

Thus, even when the CLP is designed for meeting individual client needs, the technology that should support in this individual dialogue was becoming a common tool applicable to only the "shared" user needs. Yet which things were considered "shared" seemed to be a matter of differentiation and dedifferentiation [28]. (De)differentiation refers to the blurring, covering up, merging or removing of existing differences, while differentiation means that new categories are created. The choices made here, are likely to have effects for the use and usability of the CLP. In some of the organisations the CLP was to become the means that should replace much of the other methods, checklists and additional care related documents. Here, organisations saw opportunities for a "cleanup turn" of all the older material, while the question is if this contributes to the aims of the CLP, namely realizing care more attuned to clients' wishes. In the new situation, caregivers were expected to decide for themselves which subjects needed attention in the contact with clients, so much of the (de)differentiation work was in hands of the users of the CLP:

"They [the users of the CLP] are guided in a particular direction in such a way that you can determine the things that they should take into consideration. But how deep they address these things is up to the caregiver. It gives them more responsibility; I think this is a good thing. We have given it [the CLP] so much flexibility that you can use it for all different client groups. So that is a lot. But this results, for example, in a Care Living Plan in which the subjects of orientation and disorientation are mentioned only briefly, [though these are] things that are very important on wards with many psycho-geriatric clients.” (interview with project leader CLP in large elderly care organisation) [Quote adapted from earlier published material: 27, p. 131]

To conclude, the case of the CLP shows that in order to overcome coordination and cooperation problems between organisations, as happened in the urine-incontinence case, Sting chose a local approach, supporting care organisations to develop and implement their own CLP. This approach led to interaction between design and use in multiple smaller feedback loops. User representations were created by forming multidisciplinary groups in the organization, which were expected to cover most of the differences in background and perspectives of the caregivers. This reflects a reliance on implicit user representation techniques. The mostly heterogeneous needs of users, however, posed problems for the standardisation of the CLP at a local level, as choices needed to be made what to in- and exclude and which arguments to favor before others.

\section{Conclusions}

This article aimed to analyse the interrelation between design and use, by analyzing to the Care for Better quality collaborative program. Instead of perceiving design and use as successive and linear phases, we wanted to understand what happens when design and use are approached in a more integrative sense. The research question this article aimed to answer was: How can we understand the attempts of healthcare organisations to integrate use perspectives into the design of healthcare technologies? We presented three cases that were all part of the Care for Better collaborative program. This program aimed to serve as an umbrella under which otherwise loose initiatives were bundled. This bundling had the advantage that healthcare technologies developed at one place could be easily implemented at other places. At least this was the intention of the Ministry of Health and ZonMw at the start of the program. The three projects we studied all showed different routes through which technologies were designed and implemented. The first, the incontinence case showed the struggles to include user representations in design and the complexity of integrating these user representations into the content of the guideline. With different organisations that were responsible for either design or implementation, collaboration did not commence. This was therefore a case that illustrated development of a technology without any prospects of a better implementation or a design that meets user needs.

The second case, about problem behaviour, was more successful in integrating design and use. The nine-step model was first introduced as a method in the Improvement Project and later became a part of the multidisciplinary guideline [29]. The guideline, e.g. its insistence on avoiding medication use, was at the basis of the knowledge that fed the Improvement Project. Trying to find adequate user representations was hardly an issue, as the users of the guideline were immediately also the "right" users and their participation and complaints could be directly gathered and used to make adaptations in the model. Their role was very informal yet effective to make 
rapid changes in the guideline. The project in a nursing home showed that this technology actually helped to improve the care for elderly with problem behaviour. However, for the other follow-up projects on the implementation of the guideline, it seemed to be more difficult to attract organisations to work with the guideline to improve the care delivery. Time constraints and concerns about the ambiguous results of using the guideline hindered the uptake of it. Therefore the feedback loops seemed to have played an important role in the eventual guideline, yet did not solve all implementation problems.

The third case on the Care Living Plan is different in its set up. By arranging the development and implementation on the level of individual organisations there were feedback loops between design and use created at the local level. The technology could be made locally relevant and only those aspects that mattered could be taken along. However, as we saw there were more complexities involved. More requirements were gradually added to the aims of the CLP and diversity in elderly populations and ways of arranging care made one model still difficult to realise. Thereby, there were many user representations articulated by different groups, including nurses and geriatric assistants, all with their own experiences that should be taken along. This made the CLP design too complex.

What these cases illustrate is that feedback loops are important facets of creating good and working technologies, yet they are no panacea. Feedback loops are not a "natural" phenomenon that you can observe if you have long enough time. Instead feedback loops must be explicitly organised and can in such a way help to create both better working technologies and help to start up implementation. The organisation of feedback loops was not straightforward within the Care for Better collaborative. The aims of the program organisers (ZonMw and the Ministry of Health) seemed to be more on creating congruence in otherwise separate initiatives and ensuring implementation efforts for the developed technologies. The aims of the Development Project were to create feedback moments. The aims of the Improvement Projects were to improve care in durable ways that could be benefited by healthcare technologies. Such different perspectives did not help to create a culture of learning and interacting. Moreover, arranging the projects in such a way that often one organisation is responsible for development and another is responsible for the implementation does not ensure more integrative working. Such linearity is one of the aspects social learning approaches warn for as these inhibit learning and sharing.

Finally, we have tried to show how social learning perspectives and feedback loops between design and use can be observed in just a relatively short time frame. We did involve many different actors and we did follow the course of the technology during different time frames, yet it cannot be called a longitudinal approach. Still we have shown that reciprocal interaction between design and use occurred and we managed to show some effects of these interactions. It is likely that when we would follow these interventions for longer time, we could find more interactions between design and use and even more effects, still we believe that social learning approach should not solely rely on longitudinal research methods. It seems more a matter of organising for feedback loops to occur than to see them as natural phenomenon in the innovation cycle.

\section{Acknowledgements}

We thank all the respondents of the Care for Better program for their insights into developing technologies. Thanks to three colleageaus of the institute of Health Policy and Management: Sarah Slaghuis, Annemiek Stoopendaal en Teun Zuiderent-Jerak, for doing some parts of the data collection. Thanks to Marco van Onzen for making the flow charts. This research has been funded by ZonMw, The Netherlands Organisation for Health Research and Development (Grant number: 53430001).

\section{References}

[1] Bijker, W.E. (1992) The Social Construction of Fluorscent Lighting, or How an Artifact Was Invented in Its Diffusion Stage. In: Bijker, W.E. and Law, J., Eds., Shaping Technology Building Society. Studies in Sociotechnical Change, The MIT Press, Cambridge/London, 75-102.

[2] von Hippel, E. (2005) Democratizing Innovation: The Evolving Phenomenon of User Innovation. Journal für Betriebswirtschaft, 55, 63-78.

[3] Luff, P., Hindmarsh, J. and Heath, C. (2000) Workplace Studies. Cambridge University Press, Cambridge. http://dx.doi.org/10.1017/CBO9780511628122

[4] Oudshoorn, N. and Pinch, T. (2003) How Users Matter. The Co-Construction of Users and Technology. The MIT Press, Cambridge/London. 
[5] Peine, A. and Herrmann, A.M. (2012) The Sources of Use Knowledge: Towards Integrating the Dynamics of Technology Use and Design in the Articulation of Societal Challenges. Technological Forecasting \& Social Change, 79, 1495-1512.

[6] Silverstone, R. and Haddon, L. (1996) Design and the Domestication of ICTs: Technical Change and Everyday Life. In: Silverstone, R. and Mansell, R., Eds., Communicating by Design: The Politics of Information and Communication Technologies, Oxford University Press, Oxford, 44-74.

[7] Boon, W. (2008) Demanding Dynamics. Demand Articulation of Intermediary Organisations in Emerging Pharmaceutical Innovations. Ph.D. Dissertation, Utrecht University, Utrecht.

[8] Hyysalo, S. (2007) Versions of Care Technology. Human Technology: An Interdisciplinary Journal on Humans in ICT Environments, 3, 228-247.

[9] Hyysalo, S. (2010) Health Technology Development and Use. From Practice-Bound Imagination to Evolving Impacts. Routledge, New York/London.

[10] Stewart, J. and Williams, R. (2005) The Wrong Trousers? Beyond the Design Fallacy: Social Learning and the User. In: Howcroft, D. and Trauth, E.M., Eds., Handbook of Critical Information Systems Research. Theory and Application, Edward Elgar Publishing Limited, Cheltenham/Camberley/Northampton, 195-222. http://dx.doi.org/10.4337/9781845426743.00017

[11] Zuiderent-Jerak, T., Strating, M., Nieboer, A. and Bal, R. (2009) Sociological Refigurations of Patient Safety; Ontologies of Improvement and “Acting with" Quality Collaboratives in Healthcare. Social Science \& Medicine, 69, 17131721. http://dx.doi.org/10.1016/j.socscimed.2009.09.049

[12] Strating, M.M., Nieboer, A.P., Zuiderent-Jerak, T. and Bal, R.A. (2011) Creating Effective Quality-Improvement Collaboratives: A Multiple Case Study. BMJ Quality \& Safety, 20, 344-350. http://dx.doi.org/10.1136/bmjqs.2010.047159

[13] Woolgar, S. (1991) Configuring the User: The Case of Usability Trials. In: Law, J., Ed., A Sociology of Monsters. Essays on Power Technology and Domination, Routledge, London, 58-102.

[14] Mackay, H., Carne, C., Beynon-Davies, P. and Tudhope, D. (2000) Reconfiguring the User: Using Rapid Application Development. Social Studies of Science, 30, 737-757. http://dx.doi.org/10.1177/030631200030005004

[15] Akrich, M. (1992) Beyond Social Construction of Technology: The Shaping of People and Things in the Innovation Proces. In: Dierkes, M. and Hoffmann, U., Eds., New Technology at the Outset. Social Forces in the Shaping of Technological Innovations, Campus Verlag, Frankfurt/New York, 173-190.

[16] Akrich, M. (1997) The Description of Technical Objects. In: Bijker, W.E. and Law, J., Eds., Shaping Technologies/ Building Society. Studies in Sociotechnical Change, The MIT Press, Cambridge/London, 205-224.

[17] Akrich, M. (1995) User Representations: Practices, Methods and Sociology. In: Rip, A., Misa, T.J. and Schot, J., Eds., Managing Technology in Society. The Approach of Constructive Technology Assessment, Pinter Publisher, London/ New York, 167-184.

[18] Oudshoorn, N., Rommes, E. and Stienstra, M. (2004) Configuring the User as Everybody: Gender and Design Cultures in Information and Communication Technologies. Science, Technology \& Human Values, 29, 30-63. http://dx.doi.org/10.1177/0162243903259190

[19] Berg, A.-J. and Lie, M. (1995) Feminism and Constructivism: Do Artifacts Have Gender? Science, Technology \& Human Values, 20, 332-351. http://dx.doi.org/10.1177/016224399502000304

[20] Neven, L. (2010) But Obviously Not for Me: Robots, Laboratories and the Defiant Identity of Elder Test Users. Sociology of Health \& Illness, 32, 335-347. http://dx.doi.org/10.1111/j.1467-9566.2009.01218.x

[21] Arrow, K.J. (1962) The Economic Implications of Learning by Doing. The Review of Economic Studies, 29, $155-173$. http://dx.doi.org/10.2307/2295952

[22] Rosenberg, N. (1994) Exploring the Black Box. Technology, Economics, and History (Cambridge). Cambridge University Press, Cambridge. http://dx.doi.org/10.1017/CBO9780511582554

[23] Strating, M., Zuiderent-Jerak, T., Nieboer, A.P. and Bal, R. (2008) Evaluating the Care for Better Collaborative. Results of the First Year of Evaluation. Institute of Health Policy and Management, Rotterdam, 1-132. http://oldwww.bmg.eur.nl/personal/r.bal/ZvB_ZonMW_Intermediate_report_jan08.pdf

[24] Stoopendaal, A. and Bal, R. (2013) Conferences, Tablecloths and Cupboards: How to Understand the Situatedness of Quality Improvements in Long-Term Care. Social Science \& Medicine, 78, 78-85. http://dx.doi.org/10.1016/j.socscimed.2012.11.037

[25] Institute for Healthcare Improvement (IHI) (2003) The Breakthrough Series IHI's Collaborative Model for Achieving Breakthrough Improvement. IHI Innovation Series white paper, Institute for Healthcare Improvement, Boston, 1-20.

[26] Rogers, E.M. (1995) Diffusion of Innovations. 4th Edition, The Free Press, New York.

[27] van Loon, E. and Zuiderent-Jerak, T. (2011) Framing Reflexivity in Quality Improvement Devices in the Care for Old- 
er People. Health Care Analysis, 20, 119-138. http://dx.doi.org/10.1007/s10728-011-0179-7

[28] Timmermans, S., Bowker, G.C. and Leigh Star, S. (1998) The Architecture of Difference: Visibility, Control, and Comparability in Building Nursing Interventions Classification. In: Berg, M. and Mol, A., Eds., Difference in Medicine: Unraveling Practices, Techniques, and Bodies, Duke University Press, Durham, 202-225.

[29] Verenso (2008) Richtlijn Probleemgedrag met herzienemedicatieparagraaf. Verenso, Utrecht.

[30] Timmermans, S. and Berg, M. (2003) The Practice of Medical Technology. Sociology of Health \& Illness, 25, 97-114. http://dx.doi.org/10.1111/1467-9566.00342

[31] van Loon, E., Zuiderent-Jerak, T. and Bal, R. (2014) Diagnostic Work through Evidence-Based Guidelines: Avoiding Gaps between Development and Implementation of a Guideline for Problem Behaviour in Elderly Care. Science as Culture, 23, 153-176. 
Scientific Research Publishing (SCIRP) is one of the largest Open Access journal publishers. It is currently publishing more than 200 open access, online, peer-reviewed journals covering a wide range of academic disciplines. SCIRP serves the worldwide academic communities and contributes to the progress and application of science with its publication.

Other selected journals from SCIRP are listed as below. Submit your manuscript to us via either submit@scirp.org or Online Submission Portal.
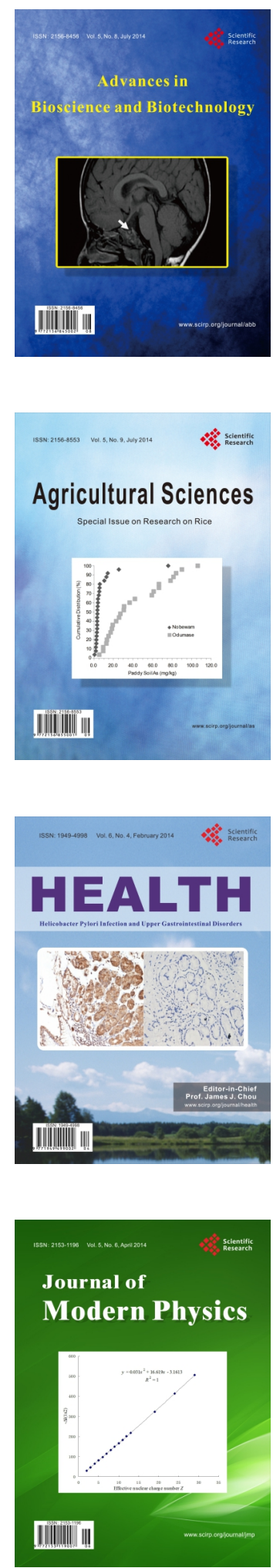
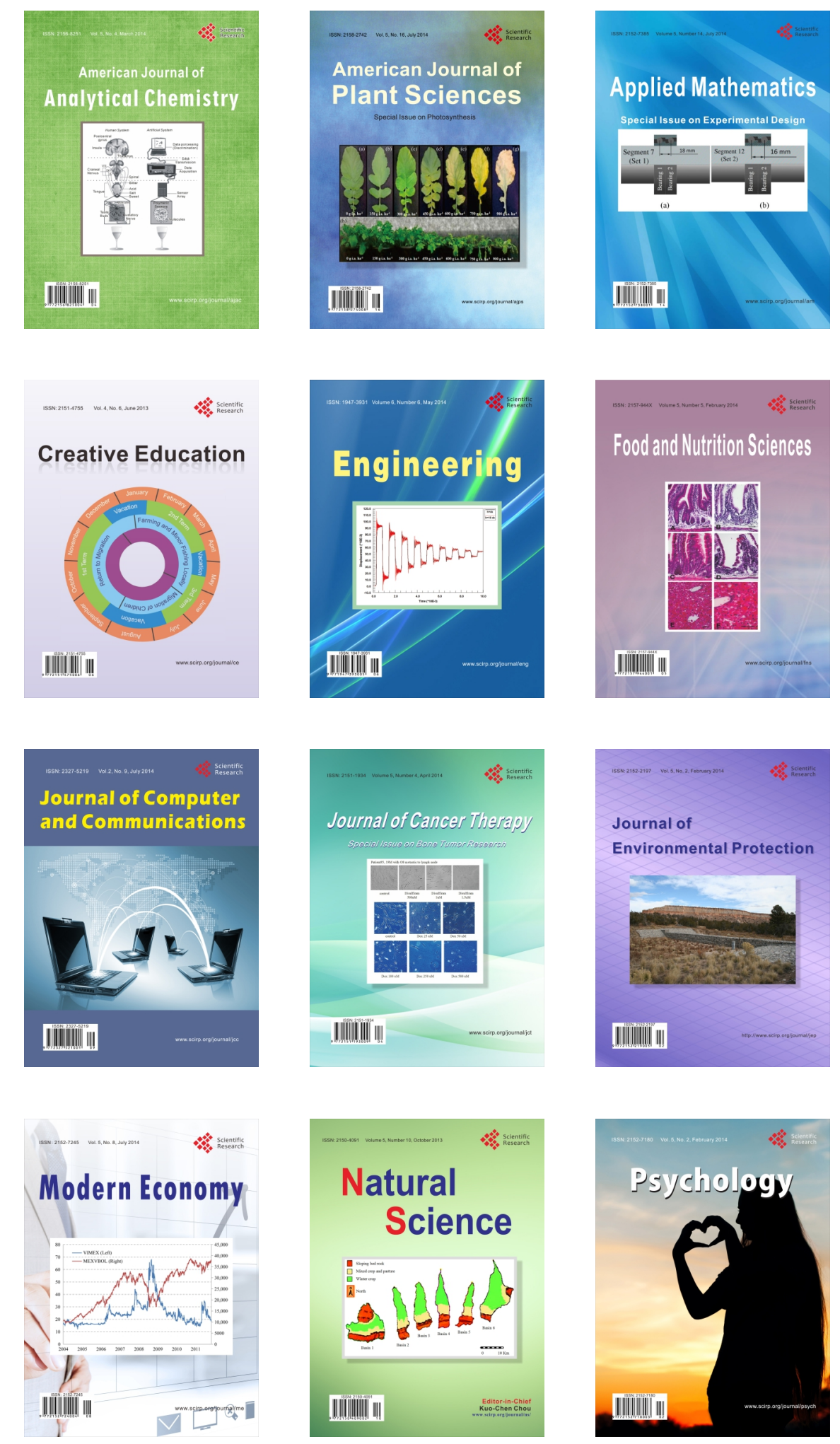